\title{
DETERMINANTS OF DOMINANCE, RESTING PLACE AND NEIGHBOUR PREFERENCES IN WRZOSÓWKA POLSKA EWES KEPT INDOORS*
}

\author{
Marcin T. Górecki, Natalia Dziwińska \\ Department of Zoology, Institute of Zoology, Poznań University Life Sciences, Wojska Polskiego 71C, \\ 60-625 Poznań, Poland \\ •Corresponding author: marcing@up.poznan.pl
}

\begin{abstract}
The aim of this study was to recognize features determining social hierarchy in Wrzosówka Polska ewes kept indoors as well as to investigate their resting place and companionship preferences. Observations (156 hours in total) were carried out in a group of 22 ewes. The social rank of sheep was determined by their age, body weight and length of horns. Social position was positively correlated with aggressive behaviour performed and negatively with aggressive behaviour received. Use of space while resting was influenced by ewe social behaviour; aggressive individuals lied more often in attractive places, namely against walls and fodder troughs compared to other animals. In general, the ewes rested by having physical contact with animals of similar rank and aggressiveness. Kinship appeared not to be important in neighbour preference. As can be concluded, social interactions influenced the use of space and neighbourhood in ewes.
\end{abstract}

Key words: social hierarchy, females, behaviour, Polish Heath Sheep

Domestic ewes are usually kept in same-sex groups besides mating and suckling periods. They are considered to be relatively unaggressive compared with females of other ruminant species. Dominance hierarchy in a group of ewes is generally recognized with difficulty (e.g. Lynch et al., 1992; Clutton-Brock et al., 2004). On the other hand, there are studies conducted on ewes of different breeds and types reporting clear dominance relationships and agonistic behaviours that are often enough to recognize social hierarchy (e.g. Lynch et al., 1985; Gräser-Hermann and Sambraus, 2001; Erhard et al., 2004). However, papers that analyse impact of ewes' traits on their social position are scarce (e.g. Gräser-Hermann and Sambraus, 2001). In general, features that could influence domestic sheep social position are: breed (Arnold

\footnotetext{
* Work financed from statutory activity.
} 
and Maller, 1974), sex (Stolba et al., 1990), age (e.g. Gräser-Hermann and Sambraus, 2001), body size and weight (e.g. Dove et al., 1974) and horn size (Preston et al., 2003).

Some native breeds of sheep were definitely lost in the twentieth century in Poland. Wrzosówka Polska (Polish Heath Sheep) was also endangered, but it was rescued. There are more than 4000 breeding Polish Heath Sheep now. The breed is protected and sometimes used for landscape conservation. Wrzosówka is one of the North European short-tailed breeds of sheep (Dýrmundsson and Niżnikowski, 2010). With regard to welfare, the absence of long tail is an advantage, because docking is not required. Polish Heath Sheep are very small, resistant and prolific. They usually deliver twins, but larger litters also occur. Ewes are not strictly seasonal in reproduction and could deliver two litters in the same year. Skins are light but durable, thus being suitable for production of sheepskin coats. One sheep produces around $2 \mathrm{~kg}$ of greasy wool per year. Their temper is vivid and they are considered to be shy. According to the standard of the breed, rams should have big horns and ewes may have small ones. Polish Heath Sheep are more similar to wild sheep than typical woolly or meat sheep breeds are (Baranowski, 1998; Niżnikowski et al., 2007; Dýrmundsson and Niżnikowski, 2010). There were papers published on some aspects of Wrzosówka behaviour, e.g. grazing and post-parturient behaviour of mothers and lambs (Sztych and Sierańska, 1994; Chrupek et al., 2006). Here are presented results of study on some aspects of social behaviour of Wrzosówka Polska ewes: clues for social dominance, place and companionship preferences.

\section{Material and methods}

A group of 22 Polish Heath Sheep ewes were used in the present study. The observations were made in the Złotniki farm belonging to the Poznań University of Life Sciences. Ewes were kept together since the beginning of 2009 with the exception of short periods during mating and early after lambing. Their lambs, born in 2010, were separated from them a couple of days before the beginning of observations. Eight of the observed females also had daughters in the experimental group (one sheep had two daughters in the group). The observed animals were in their second (9 sheep) or third (13 ewes) year of life. Their age on 1 August 2010 ranged from 15 to 29 months (mean \pm SD: $23.3 \pm 6.5$ months). All observed sheep suckled lambs in 2010, with the exception of three animals that were in the second year of life. Body weight of the observed individuals ranged from 26.3 to $52.8 \mathrm{~kg}$ (mean \pm SD: $38.2 \pm 6.5 \mathrm{~kg}$ ). With the exception of two hornless animals all ewes were horned. The length of right horns ranged from 3 to $18 \mathrm{~cm}$ (mean \pm SD: $8.2 \pm 5 \mathrm{~cm}$ ), whereas the length of left horns ranged from 2.7 to $3.5 \mathrm{~cm}$ (mean \pm SD: $6 \pm 3.5 \mathrm{~cm}$ ). The lengths of right and left horns were strongly correlated (correlation coefficient $\mathrm{r}=0.77, \mathrm{P}=0.0001$ ). The mean length of horns ranged from 3.25 to $15 \mathrm{~cm}$ (mean $\pm \mathrm{SD}: 7.1 \pm 3.9 \mathrm{~cm}$ ).

Ewes were kept in a pen $(6 \times 13 \mathrm{~m})$ with straw used as bedding and also usually had the possibility to use an outdoor paddock (approx. $0.5 \mathrm{ha}$ ) during daytime. There 
were two watering troughs and four cribs for silage and straw in the pen. Water was changed every day. The silage was delivered in two cribs every day before noon and straw was given in all four cribs every 2-3 days after silage delivery.

Each ewe could be recognized after marking with a spray appropriate for animal marking. Numbers (approx. 20-30 cm) were painted on the wool. At the beginning of the observation period, sheep were weighed and their horns were measured.

Altogether $156 \mathrm{~h}$ of direct observation were conducted by the same observer (N.D.). in July and August 2010 after preliminary observation. Observations were carried out between 7:30 AM and 6:30 PM during 20 observation days (5-10 h observations per day). Sheep seemed to be quickly accustomed to the presence of the observer. Moreover, binoculars made the observation of sheep easier.

The continuous recording and sampling of all occurrences of behaviour (Altmann, 1974), namely social behaviour (both agonistic: head clashing, butting, shoulder pushing, front kicking, bowing head, stumping, urination, making room; and affiliative: lying together, rubbing, wool nibbling), was carried out. Observations were manually recorded. Moreover, spatial distribution of sheep during resting in the sheepfold was noted at least once a day (altogether 26 scans). To investigate possible resting place preference, the pen in the sheepfold was divided into four virtual squares of roughly the same area. The squares at the front of the pen (at the corridor) had numbers 1 and 4; those at the back (at the sheepfold wall) had numbers 2 and 3. Also lying against sheepfold wall and fodder troughs were analysed.

Agonistic behaviour was used to calculate dominance indexes (DI) for every sheep according to the formula (developed by Sambraus, 1975):

$$
D I=a /(a+b)
$$

where:

$a$ - number of individuals dominated by a given animal,

$b$ - number of individuals which dominated a given animal.

As distribution of DI did not significantly deviate from normality (KolmogorovSmirnov $\mathrm{Z}=0.748, \mathrm{P}=0.63$ ) it was not necessary to apply transformation recommended by Beilharz and Zeeb (1982).

Out of 231 possible dyads, dominance-submission relationships were recognized in 119 (51.5\%). (For comparison, Guilhem et al. (2000) observed 54 and 62\% of all possible dyads in two consecutive years of studying captive mouflon ewes group of size very similar to our group.) DI was not taken into account if at least six (i.e. $28.6 \%$, arbitrarily chosen) dominance-submission relations for a given sheep were not recognized, thus DI of two sheep were rejected from further calculations. (For comparison, Hass (1991) ranked wild bighorn sheep ewes of known interactions with at least $10 \%$ of other herd members.) To check if social position influences resting place, sheep were divided into two groups: first with $\mathrm{DI}<0.5$ and second with $\mathrm{DI}>0.5$ (no animal had DI $=0.5$ ).

On the basis of affiliative behaviour (namely lying with physical contact) companionship preferences were evaluated. The formula used was: 


$$
Z=(o-e) / \sqrt{ } e
$$

where:

$o$ - number of observed contacts,

$e$ - number of expected contacts,

$Z>1.96$ means that one individual is preferred by another (Van Dierendonck et al., 2009).

$\mathrm{Z}$ was calculated for every pair of animals twice, because preference need not be reciprocal.

Pearson correlation was used to evaluate relations between different forms of behaviour and possible influence of sheep physical and behavioural traits on dominance index. Moreover, multivariate ANOVA was applied to investigate DI relations with other traits.

Chi-square test, Fisher exact test and Pearson correlation were used to examine sheep place and companionship preferences. Data of sheep no. 7 resting under a trap leading to entrance were not included into "lying against wall" in calculations of correlations with ID and social behaviour, because other sheep did not try to use this place and did not compete for it. Anyway, inclusion of data mentioned above did not change the results.

\section{Results}

As observed, the age of sheep significantly influenced their body weight $(\mathrm{r}=0.521, \mathrm{P}<0.05)$, but length of horns was not significantly correlated with sheep age $(\mathrm{P}>0.05)$. Body weight and length of horns also were not significantly correlated $(\mathrm{P}>0.05)$.

Ewes displayed several forms of social behaviour, both agonistic (head clashing, butting, shoulder pushing, front kicking, bowing head, stumping, urination, making room) and affiliative (lying together, rubbing, wool nibbling). Fights did not attract other sheep and they did not join. The intervention in fight was observed once: the intervener went among fighters to stop their combat. More aggressive sheep also rested more often having physical contact with other sheep $(\mathrm{r}=0.563, \mathrm{P}=0.006)$ than the other ewes.

Social position (expressed as DI) appeared to be correlated with age $(\mathrm{r}=0.688$, $\mathrm{P}<0.01$; Figure 1), body weight $(\mathrm{r}=0.623, \mathrm{P}<0.01$; Figure 2$)$ and length of horns (for horned ewes only: $\mathrm{r}=0.532, \mathrm{P}<0.05$; when two hornless sheep also included: $\mathrm{r}=0.42, \mathrm{P}=0.065$; Figure 3 ).

All three traits appeared to influence DI significantly also in multivariate ANOVA (age: $\mathrm{P}=0.001$, body weight: $\mathrm{P}=0.024$, length of horns: $\mathrm{P}=0.001 ; \mathrm{R}^{2}=0.78$ ). Dominance indexes of mothers and their daughters were not significantly correlated $(\mathrm{P}>0.05)$. 
dominance_index

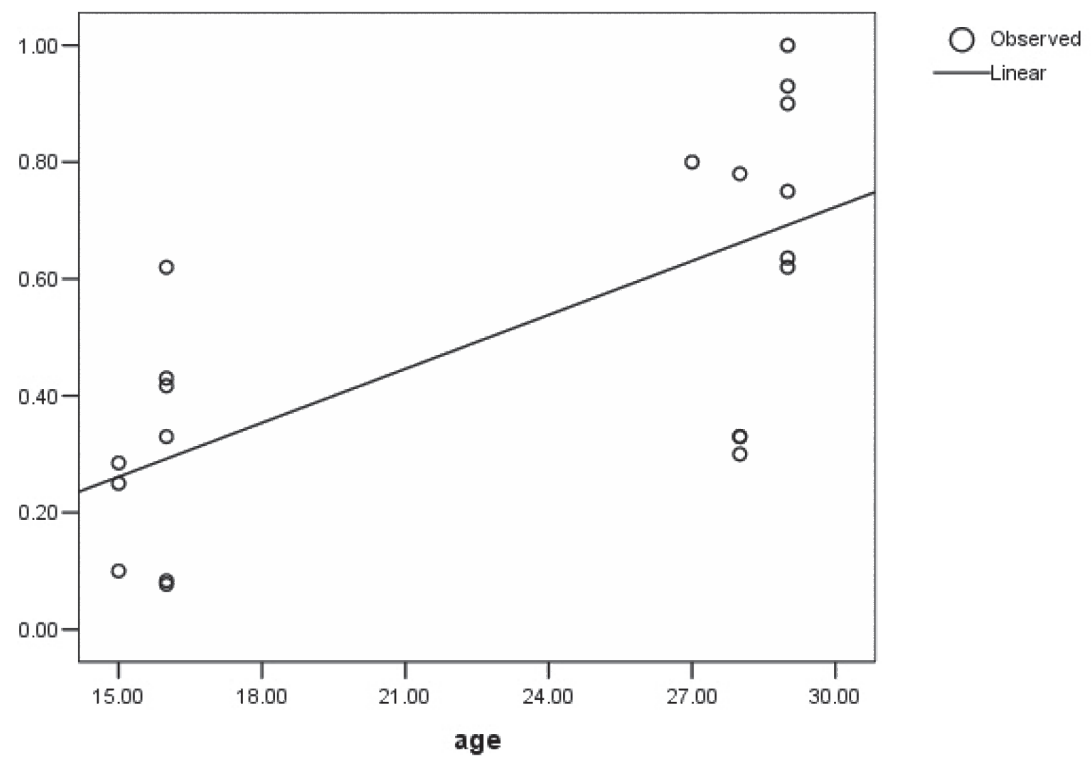

Figure 1. The relation between age (months) and social position (expressed as dominance index) in Wrzosówka Polska ewes $\left(\mathrm{n}=20, \mathrm{r}=0.688, \mathrm{R}^{2}=0.474, \mathrm{P}<0.01\right)$

\section{dominance_index}

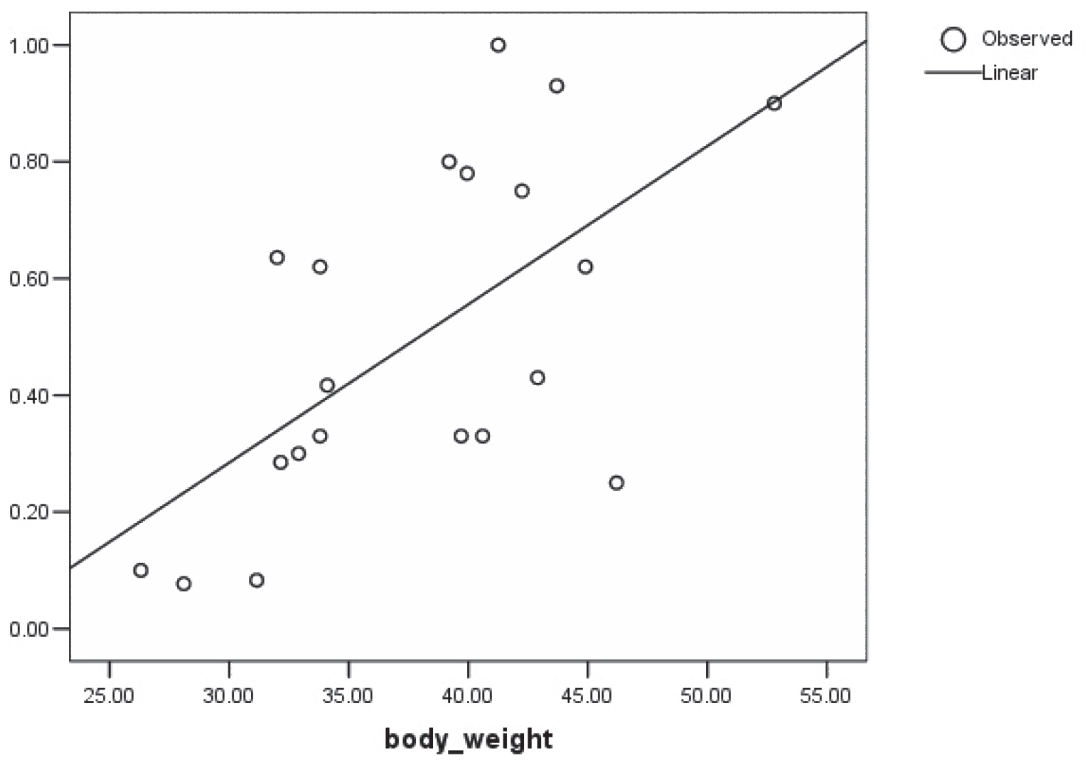

Figure 2. The relation between body weight $(\mathrm{kg})$ and social position (expressed as dominance index) in Wrzosówka Polska ewes $\left(\mathrm{n}=20, \mathrm{r}=0.623, \mathrm{R}^{2}=0.388, \mathrm{P}<0.01\right)$ 


\section{dominance_index}

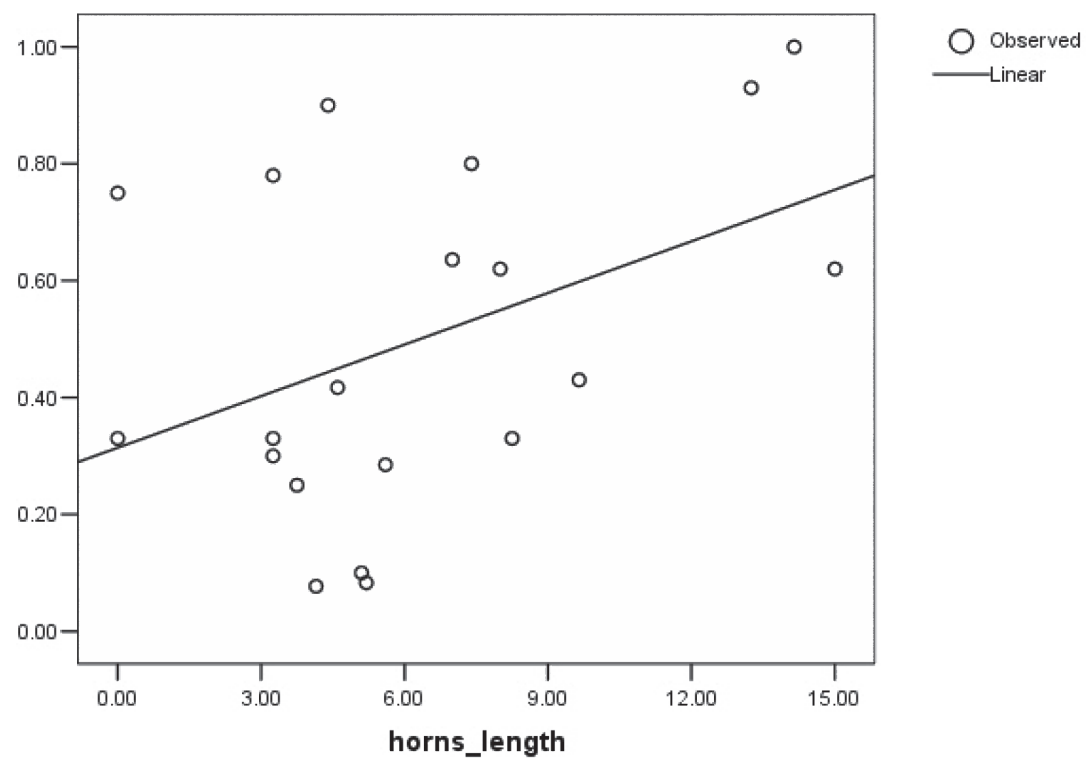

Figure 3. The relation between length of horns $(\mathrm{cm})$ and social position (expressed as dominance index) in Wrzosówka Polska ewes $\left(\mathrm{n}=20, \mathrm{r}=0.42, \mathrm{R}^{2}=0.177, \mathrm{P}=0.065\right)$

DI was positively correlated with aggressive behaviour performed $(\mathrm{r}=0.744$, $\mathrm{P}<0.01$ ). Social position was negatively correlated with aggressive behaviour received $(r=-0.734, \mathrm{P}<0.01)$ and giving room for other sheep $(\mathrm{r}=-0.391, \mathrm{P}=0.088)$. Also some significant or marginally significant correlations between traits determining DI and social behaviour were calculated, e.g. older sheep were less often attacked $(\mathrm{r}=-0.585, \mathrm{P}<0.05)$, heavier sheep less often withdrew $(\mathrm{r}=-0.426, \mathrm{P}<0.05)$, etc.

Fourteen sheep $(63.6 \%)$ revealed significant "preference" $(\mathrm{P}<0.05)$ for one of four virtual squares in the pen. Some sheep had their favourite resting places, e.g. under trap leading to entrance (sheep no. 7 was observed there for $53.8 \%$ of scans) or just next to the door (sheep no. 6 was always observed resting there). Sheep no. 12 was often $(34.6 \%$ of scans) found standing at the door when other sheep were lying.

Sheep were observed in four virtual squares for $42.94 \%$ (no. 2), $28.07 \%$ (no. 3), $22.02 \%$ (no. 4) and $6.97 \%$ (no. 1 ) of records $\left(\chi^{2}=85.49\right.$, df $=3, \mathrm{P}<0.0001$ ). Thus parts of the pen adjoining the wall of the sheepfold ( 2 and 3 ) were chosen by sheep more often than those adjoining the corridor (1 and 4). A significant relationship between DI and square preference was not confirmed $(\mathrm{P}>0.05)$. However, resting against walls and troughs for fodder was correlated at marginally significant level with DI $(r=0.425, P=0.062)$. Sheep lying more often against walls and troughs ap- 
peared to be more aggressive $(\mathrm{r}=0.55, \mathrm{P}=0.008)$ and to lay more often with physical contact with other ewes $(\mathrm{r}=0.571, \mathrm{P}=0.005)$ compared to the other animals.

Out of possible 462 pairs of sheep companionship preference, 272 were observed (i.e. in the case of 190 pairs, animals were never observed resting with physical contact with another ewe) and out of these 49 preferences of companionship appeared to be significant (32 reciprocal). Every ewe had 1-4 favourite neighbours.

Ewes did not prefer the companionship of their relatives (mothers, daughters or sisters), since relatives were only preferred only in 3 cases (out of 20 possible pairs). Preference for sheep born in the same year appeared to be significant in older individuals $\left(\chi^{2}=3.94, \mathrm{df}=1, \mathrm{P}=0.047\right)$, but not in ewes in their second year of life $\left(\chi^{2}=0.08, \mathrm{df}=1, \mathrm{P}>0.05\right)$. On the other hand, aggressiveness $(\mathrm{r}=0.357, \mathrm{P}<0.05)$ and DI $(r=0.465, P<0.01)$ of the ewe and their preferred neighbours were significantly correlated.

\section{Discussion}

Gräser-Hermann and Sambraus (2001) observed two interesting phenomena connected with fighting in Friesland ewes: group fighting and intervention; only the latter was observed once in the present study.

Social position of the ewes observed in the present study was determined by age, body weight and horn length. Age-related social hierarchies were documented both in domestic and wild sheep (Arnold and Maller, 1974; Bennett, 1986; Eccles and Shackleton, 1986; Festa-Bianchet, 1991; Hass, 1991; Guilhem et al., 2000; Gräser-Hermann and Sambraus, 2001; Favre et al., 2008). Although the statement that social position of old animals declines with increasing age is controversial, there is agreement that young animals have low rank.

As found in the present study, body weight was positively correlated with social position. Gräser-Hermann and Sambraus (2001) observed such a relationship in Friesland ewes. Body size and weight were also reported to influence social hierarchy in domestic wethers (Dove et al., 1974; Lobato and Beilharz, 1979) and also in bighorn ewes (Favre et al., 2008). However, such a relationship was not observed in domestic wethers by Arnold and Maller (1974).

Moreover, horn length appeared to affect social hierarchy in Wrzosówka ewes observed in the present study. According to the best knowledge of the authors, there are no published data describing the effect of horn length on the social hierarchy of domestic ewes. However, Soay male sheep with normal horns are apparently more successful in competition for mating opportunities than those with deformed (scurred) horns; size of horns is also an important factor that influences mating success within rams with normal horns (Preston et al., 2003; Stevenson et al., 2004). Similarly, in rams of bighorn sheep social rank is affected by the size of horns (Geist, 1971), but results about possible influence of horns size on social rank of females of this species are inconsistent at best (Eccles and Shackleton, 1986; Favre et al., 2008). Although it was well documented that social hierarchy of both male and female do- 
mestic goats is strongly influenced by their hornedness (e.g. Sambraus, 1971; Shank, 1972; Barroso et al., 2000; Górecki, 2004), no data about horn size effect on social rank exist. In his report on female goats, Pretorius (1970) wrote that "the shape and size of the horns determined effectiveness of hooking", but this statement was not confirmed with any calculations. Côté (2000) did not find a relationship between horn size and social rank in female mountain goat. Locati and Lovari (1991) found such a relationship in Pyrenean chamois females: social rank was correlated with horn size in animals aged 2-7 years.

As illustrated in the present study, highly ranked ewes were more aggressive compared to the other animals. These results are in agreement with the data of Eccles and Shackleton (1986) concerning bighorn sheep. It was also reported that older domestic and wild sheep are more aggressive than younger individuals (Stolba et al., 1990; Hass, 1991).

In contrast to the present results, Guilhem et al. $(2000,2002)$ found that social position of captive mouflon ewes was related with the social positions of their dams. Moreover, the above authors suggested that older sheep (those with higher social position) gave birth earlier in the year and ewes born earlier in the year dominate others born later in the same year. Indeed, as observed in sheep (e.g. feral Soay sheep and mouflon), the older the ewes, the earlier in the year they delivered (Clutton-Brock et al., 1992; Bon et al., 1993). In bighorn sheep, however, reports on maternal age influence on offspring birth date are controversial (Festa-Bianchet, 1988; Favre et al., 2008). Lack of correlation between the dominance index of dams and their female offspring in the present study may be connected with the small sample. Moreover, dams of adult ewes were born in the same year, thus variability in their offspring's date of birth was probably smaller compared to that of the mouflons studied by Guilhem et al. (2000, 2002).

The majority of sheep that were observed in the present study had a 'preferred' part (virtual square) within the pen. It was not related with dominance index, possibly as a result of the inadequate division of the pen into only four squares. However, more aggressive sheep with higher social position rested more often against walls and troughs for fodder than less aggressive ewes. This is consistent with results reported by Marsden and Wood-Gush (1986) and Færevik et al. (2005) that sheep prefer to rest against walls, thus such places can be considered as resources. Sheep compete not only for feed (Arnold and Maller, 1974; Erhard et al., 2004; Bøe and Andersen, 2010) and sexual partners (e.g. Synnot and Fulkerson, 1984), but also for other resources, e.g. resting place (Bøe et al., 2006). Sherwin and Johnson (1987) reported that wethers of higher rank more often rested in the shadow than castrates of lower rank. Interestingly, Jørgensen et al. (2009) did not observe reduced number of aggressive social interactions in sheep kept in pens with additional walls.

A preference to rest with physical contact with relatives was not observed in the present study. There is a controversy in the literature concerning the bonds of sheep with their relatives. It seems that different species of wild sheep and different breeds of domestic sheep differ very clearly in relations with kin (Lawrence, 1990; Hinch et al., 1990; Festa-Bianchet, 1991; Guilhem et al., 2000). 
Wrzosówka Polska appeared to be rather more similar to Scottish Blackface than Merino, as the latter breed is known to form long-lasting mother-daughter bonds.

Wrzosówka ewes preferred companionship of animals of similar rank and aggressiveness. This finding is in agreement with observations on mouflon ewes published by Guilhem et al. (2000). However, these authors claimed that proximity during resting might be more connected with age than with rank. They found that yearling mouflon females preferred individuals of their own age class as neighbours and old females (older than four years) tended to associate with specimens older than yearlings, but ewes in their third and fourth year of life did not show any preference in associating with specimens of a particular age group. In the present study preference for neighbours similar in rank and aggressiveness could also be explained with age, as ewes in their third year of life preferred sheep of the same age, although younger ewes did not reveal age-related preferences.

In conclusion, the social hierarchy in Polish Heath Sheep observed in the present study was determined by age, body weight and length of horns. It was found that social interactions had a significant influence on the use of space and neighbourhood in ewes.

\section{References}

A $1 \mathrm{t}$ m a n n J. (1974). Observational study of behavior: sampling methods. Behaviour, 49: 227-267.

A rn old G.W., M a ll e r R.A. (1974). Some aspects of competition between sheep for supplementary feed. Anim. Prod., 19: 309-319.

B a r a n ow sk i P. (1998). Chosen imported and native breeds and varieties of sheep - history of their origin (in Polish). Akademia Rolnicza w Szczecinie, Szczecin, Poland, 29 pp.

B a r r o s o F.G., A l a d o s C.L., B o z a J. (2000). Social hierarchy in the domestic goat: Effect on food habits and production. Appl. Anim. Behav. Sci., 69: 35-53.

B e il h ar z R.G., Z e e b K. (1982). Social dominance in dairy cattle. Appl. Anim. Ethol., 8: 79-97.

B e n n e t t B. (1986). Social dominance in female bighorn sheep. Zoo Biol., 5: 21-26.

B ø e K.E., A n d e r s e n I.L. (2010). Competition, activity budget and feed intake of ewes when reducing the feed space. Appl. Anim. Behav. Sci., 125: 109-114.

Bø e K.E., B e rg S., A n d e r s e n I.L. (2006). Resting behaviour and displacements in ewes - effects of reduced lying space and pen shape. Appl. Anim. Behav. Sci., 98: 249-259.

B on R., Dardaillon M., Estevez I. (1993). Mating and lambing periods as related to age of female mouflon. J. Mammal., 74: 752-757.

Chrupek D., Groberek J., Niżnikowski R., Brzostowski H., Strzelec E., Popielarczyk D., Marciniec M. (2006). Characteristic of Polish heath sheep grazing behaviour on fallow lands during vegetative period, concerning pasturage time and weather conditions. Arch. Tierzucht, 49 (SI): 353-358.

Clutt on - B rock T.H., P e m b e r t on J.M., Couls on T., S t e ven son I.R., M a c Coll A.D.C. (2004). The sheep of St Kilda. In: Soay sheep. Dynamics and selection in an island population, Clutton-Brock TH., Pemberton J.M. (eds). Cambridge University Press, Cambridge, UK, pp. 17-51.

Clutt on-Brock T.H., Price O.F., A 1 b on S.B., Jew ell P.A. (1992). Early development and population fluctuations in Soay sheep. J. Anim. Ecol., 61: 381-396.

C ô té S.D. (2000). Dominance hierarchies in female mountain goats: stability, aggressiveness and determinants of rank. Behaviour, 137: 1541-1566.

D o v e H., B e i 1 h a r z R.G., B l a ck J. (1974). Dominance patterns and positional behaviour of sheep in yards. Anim. Prod., 19: 157-168.

Dýrmundss on Ó.R., Niznikowski R. (2010). North European short-tailed breeds of sheep: a review. Animal, 4: 1275-1282. 
Eccles T.R., Shackleton D.M. (1986). Correlates and consequences of social status in female bighorn sheep. Anim. Behav., 34: 1392-1401.

E rha a d H.W., F à bre g a E., S t a n w or th G., E $1 \mathrm{~s}$ t on D. (2004). Assessing dominance in sheep in a competitive situation: level of motivation and test duration. Appl. Anim. Behav Sci., 85: 277-292.

Færevik G., A ndersen I.L., Bøe K.E. (2005). Preference of sheep for different types of pen flooring. Appl. Anim. Behav. Sci., 90: 265-276.

F a vre M., Martin J.G.A., Fe sta-Bi an chet M. (2008). Determinants and life-history consequences of social dominance in bighorn ewes. Anim. Behav., 76: 1373-1380.

Fe st a- B i a n chet M. (1988). Age-specific reproduction of bighorn ewes in Alberta, Canada. Can. J. Mammal., 69: 157-60.

Fe sta-Bi an chet M. (1991). The social system of bighorn sheep: grouping patterns, kinship and female dominance rank. Anim. Behav., 42: 71-82.

G e is t V. (1971). Mountain sheep: a study in behavior and evolution. University of Chicago Press, Chicago, USA, 383 pp.

G ó r e c k i M.T. (2004). Hierarchy in a group of domestic goat (Capra hircus) females. EJPAU, 7, 2.

Gräser-Hermann Ch., S a mbraus H.H. (2001). The social behaviour of East Friesian dairy sheep in larger groups. Arch. Tierzucht, 44: 421-433.

Guilh e m C., B idea u E., Gerard J.F., M a ublan c M.L. (2000). Agonistic and proximity patterns in enclosed mouflon (Ovis gmelini) ewes in relation to age, reproductive status and kinship. Behav. Processes, 50: 101-112.

Guilh e m C., Gerard J.F., B id e a u E. (2002). Rank acquisition through birth order in mouflon sheep (Ovis gmelini) ewes. Ethology, 108: 63-73.

H a s s C.C. (1991). Social status in female bighorn sheep (Ovis canadensis): expression, development and reproductive correlates. J. Zool. Lond., 225: 509-523.

H in ch G.N., Ly n ch J.J., E 1 w in R.L., G re en G.C. (1990). Long term associations between Merino ewes and their offspring. Appl. Anim. Behav. Sci., 27: 93-103.

Jørgensen G.H.M., Andersen I.L., Bøe K.E. (2009). The effect of different pen partition configurations on the behaviour of sheep. Appl. Anim. Behav. Sci., 119: 66-70.

L a w r e n c e A.B. (1990). Mother-daughter and peer relationships of Scottish hill sheep. Anim. Behav., 39: 481-486.

L obato J.F.P., B eilharz R.G. (1979). Relation of social dominance and body size to intake of supplements in grazing sheep. Appl. Anim. Ethol., 5: 233-239.

L o c at i M., L ovari S. (1991). Clues for dominance in female chamois: age, weight, or horn size? Agg. Behav., 17: 11-15.

Ly n ch J.J., H in ch G.N., A d a m s D.B. (1992). The behaviour of sheep: biological principles and implications for production. CAB International, Wallingford, UK, $237 \mathrm{pp}$.

Lynch J.J., Wood-Gush D.G.M., Davies H.I. (1985). Aggression and nearest neighbours in a flock of Scottish Blackface ewes. Biol. Behav., 10: 215-225.

Marsden M.D., Wood-Gush D.G.M. (1986). The use of space by group housed sheep. Appl. Anim. Behav. Sci., 15, p. 178.

Niżnikowski R., Popielarczyk D., Strzelec E., Brudka G. (2007). Level of reproduction traits of highly-prolific Polish Heath sheep used in the rare breeds conservation program (in Polish). Ann. UMCS EE, 25: 109-117.

Preston B.T., Stevenson I.R., Pemberton J.M., Coltman D.W., Wilson K. (2003). Overt and covert competition in a promiscuous mammal: the importance of weaponry and testes size to male reproductive success. Proc. R. Soc. Lond. B, 270: 633-640.

Pret or i u s P.S. (1970). Effect of aggressive behaviour on production and reproduction in the Angora goat (Capra hircus Angoraensis). Agroanimalia, 2: 161-164.

$\mathrm{S}$ a $\mathrm{m}$ b r a u s H.H. (1971). The social behaviour of domesticated goats (in German). Z. Säugetierkunde, 36: $220-224$.

S a m b r a u s H.H. (1975). Observations and reflections on the social order of cattle (in German). Züchtungskunde, 47: 8-14.

S h a n k C.C. (1972). Some aspects of social behaviour in a population of feral goats. Z. Tierpsychol., 30: $488-528$. 
S h e rw in C.M., J o h n s on K.G. (1987). The influence of social factors on the use of shade by sheep. Appl. Anim. Behav. Sci., 18: 143-155.

S t e ven s on I.R., M arrow P., Pre st on B.T., P e m berton J.M., W il s o n K. (2004). Adaptive reproductive strategies. In: Soay sheep. Dynamics and selection in an island population, CluttonBrock TH., Pemberton J.M. (eds). Cambridge University Press, Cambridge, UK, pp. 243-275.

S tolba A., H in ch G.N., Ly n c h J.J., A d a m s D.B., Munro R.K., D a vi e s H.I. (1990). Social organization of Merino sheep of different ages, sex and family structure. Appl. Anim. Behav. Sci., 8: 243-252.

S y n n o t A.L., F u 1 k e r s o n W.J. (1984). Influence of social interactions between rams on their serving capacity. Appl. Anim. Behav. Sci., 11: 283-289.

S z t y c h D., S i e r án s k a B. (1994). Post-parturient behaviour of ewes and lambs of Heath Sheep (in Polish). Zesz. Nauk. PTZ, 13: 117-124.

VanDierendonck M.C., de Vries H., Schilder M.B.H., Colenbrander B., Porha 11 s dót t ir A.G., S i gurjóns dót t i r H. (2009). Interventions in social behaviour in a herd of mares and geldings. Appl. Anim. Behav. Sci., 116: 67-73.

Received: 7 II 2013

Accepted: 30 VIII 2013 